\title{
Faktor-Faktor yang Mempengaruhi Pajak Pertambahan Nilai dan Pajak Penjualan Atas Barang Merwah Di Indonesia
}

\author{
Moraulina Marsella Simarmata \\ Bastari \\ Fakultas Ekonomi dan Bisnis Universitas Sumatera Utara \\ Email: marsella100392@gmail.com
}

\begin{abstract}
PPN (Value-Added Tax) and PPnBM (Luxury Goods Sales Tax) are kind of taxes recognized in Indonesia, and are classified into indirect tax which are imposed to the consumption in every level of production and distribution. As the taxes on consumption, $P P N$ and PPnBM are highly dependent on the general economic condition. The indicators of macro economy may have influence on the revenues of PPN and PPnBM every year, and so is the amount of PKP (Taxable Entrepreneur) as PPN Collector according to the prevailing PPN Law. Therefore, the objective of the research was to find out how the amount of PKP, PDB, export value, import value, inflation, consumption expense, population and SBI interest rates influenced the revenues of PPN and PPnBM in Indonesia from 1986 until 2015. Ordinary Least Square method was applied for the analysis with multiple linear regression equation. The results showed that the amount of $P K P, P D B$, export value, import value, inflation, consumption expense, population and SBI interest rates simultaneously had a significant influence on the revenues of PPN and PPnBM in Indonesia. Partially, the amount of PKP, PDB, Export value, import value, consumption and population had positive influence on the revenues of $P P N$ and $P P n B M$, whereas inflation and SBI interest rates had negative influence on the revenues of PPN and PPnBM in Indonesia..
\end{abstract}

Keywords: Amount of PKP, PDB, Export Value, Import Value, Inflation, Consumption, Population, SBI Interest Rates, Revenues of PPN and PPnBM.

\section{PENDAHULUAN}

D ajak merupakan salah satu komponen penting dalam pembangunan ekonomi di setiap Negara karena pajak merupakan salah satu sumber penghasilan negara yang terbesar. Menurut Undang-Undang Nomor 6 Tahun 1983 Tentang Ketentuan Umum dan Tata Cara Perpajakan Sebagaimana telah Beberapa kali diubah Terakhir dengan Undang-Undang Nomor 6 Tahun 2009 Pasal 1, ayat 1 menyatakan bahwa 
"pajak adalah kontribusi wajib kepada Negara yang terutang oleh orang pribadi atau badan yang bersifat memaksa berdasarkan Undang- Undang, dengan tidak mendapatkan imbalan secara langsung dan digunakan untuk keperluan Negara bagi sebesar-besarnya kemakmuran rakyat." Untuk itu, sebagai warga Negara Indonesia tentunya dapat membayar pajak sesuai dengan peraturan perundang-undangan yang berlaku.

Salah satu tolak ukur dari keberhasilan ekonomi suatu negara dapat dilihat dari angka pertumbuhan ekonomi negara tersebut. Peran pemerintah sebagai stabilisator perekonomian dapat dijalankan dengan mengeluarkan kebijakan-kebijakan untuk mengurangi kesenjangan dalam perekonomian. Salah satu kebijakan yang sangat penting dilakukan oleh pemerintah dalam pengendalian perekonomian adalah kebijakan fiskal. Kebijakan fiskal berhubungan erat dengan kegiatan pemerintah sebagai pelaku sektor publik. Kebijakan fiskal dalam hal penerimaan pemerintah mempunyai instrumen utama yaitu perpajakan. Penerimaan pajak memiliki peranan yang strategis dalam menunjang operasi fiskal pemerintah. Pajak disamping sebagai sumber penerimaan utama negara (budgetary), juga mempunyai fungsi sebagai alat untuk mengatur (regulatory) dan mengawasi kegiatan-kegiatan swasta dalam perekonomian (Wibowo 2000).

Pajak Pertambahan Nilai (PPN) dan Pajak Penjualan atas barang mewah (PPnBM ) merupakan salah satu jenis pajak yang ada di Indonesia yang bersifat tidak langsung dan dikenakan terhadap konsumsi pada setiap tingkatan produksi atau distribusi. Meskipun pengenaan PPN dilakukan terhadap nilai tambah yang terjadi dalam setiap tingkatan produksi dan/atau distribusi barang atau jasa, namun beban atas pajak ini secara tidak langsung ditanggung oleh konsumen akhir. (Untung Sukardji, 2006). Dan PPnBM yang dikenakan atas barang impor.

Sebelum PPN diberlakukan tahun 1984, di Indonesia diberlakukan Undang-undang Pajak Penjualan (PPN) Tahun 1951 yang merupakan warisan kolonial Belanda. Namun keberadaan Pajak Penjualan (PPN) ini dirasakan masih memiliki beberapa kekurangan maka dilakukanlah reformasi perpajakan (tax reform) pada tahun 1984 dengan dikeluarkannya Undang-undang PPN yaitu Undang-Undang Nomor 8 Tahun 1983 tentang Pajak Pertambahan Nilai Barang dan Jasa dan Pajak Penjualan atas Barang Mewah. (Wibowo, 2000). 
Berdasarkan Undang-Undang Republik Indonesia No. 42 Tahun 2009 tentang Pajak Pertambahan Nilai (PPN) dan Pajak Penjualan atas Barang Mewah (PPnBM ), merupakan pajak yang dikenakan atas penyerahan Barang Kena Pajak yang dikenakan atas konsumsi barang kena pajak yang tergolong mewah di dalam daerah pabean. Pajak penjualan atas barang mewah dikenakan hanya satu kali pada waktu penyerahan BKP yang tergolong barang mewah oleh pengusaha yang menghasilkan atau pada waktu impor.

Adapun yang menjadi tujuan penelitian dalam penulisan penelitian ini adalah : (1)Untuk menganalisis pengaruh jumlah Pengusaha Kena Pajak terhadap penerimaan PPN dan PPnBM di Indonesia.; (2)Untuk menganalisis pengaruh Produk Domestik Bruto terhadap penerimaan PPN dan PPnBM di Indonesia; (3)Untuk menganalisis pengaruh nilai ekspor terhadap penerimaan PPN dan PPnBM di Indonesia; (4)Untuk menganalisis pengaruh nilai impor terhadap penerimaan PPN dan PPnBM di Indonesia; (5)Untuk menganalisis pengaruh tingkat inflasi terhadap penerimaan PPN dan PPnBM di Indonesia; (6) Untuk menganalisis pengaruh pengeluaran konsumsi berpengaruh terhadap penerimaan PPN dan PPnBM di Indonesia; (7)Untuk menganalisis pengaruh jumlah penduduk terhadap penerimaan PPN dan PPnBM di Indonesia; (8)Untuk menganalisis pengaruh suku bunga SBI terhadap penerimaan PPN dan PPnBM di Indonesia; (9)Untuk menganalisis pengaruh jumlah PKP, PDB, Nilai Ekspor, Nilai Impor, inflasi, pengeluaran konsumsi, jumlah penduduk dan suku bunga secara simultan mempengaruhi penerimaan PPN dan PPnBM di Indonesia.

Dari kerangka konseptual di bawah, dapat dilihat bahwa peneliti ingin melihat bagaimana pengaruh variabel independen yaitu PKP $\left(X_{1}\right)$, $\operatorname{PDB}\left(X_{2}\right)$, Nilai ekspor $\left(X_{3}\right)$, Nilai impor $\left(X_{4}\right)$, inflasi $\left(X_{5}\right)$, Pengeluaran Konsumsi $\left(X_{6}\right)$ dan Jumlah Penduduk $\left(X_{7}\right)$, dan Suku bunga $\left(X_{8}\right)$ terhadap variabel dependen yaitu penerimaan PPN dan PPnBM di Indonesia.

Pada penulisan penelitian ini, penulis menjelaskan variabel-variabel yang saling mempengaruhi dalam bentuk kerangka konseptual penelitian sebagai berikut : 


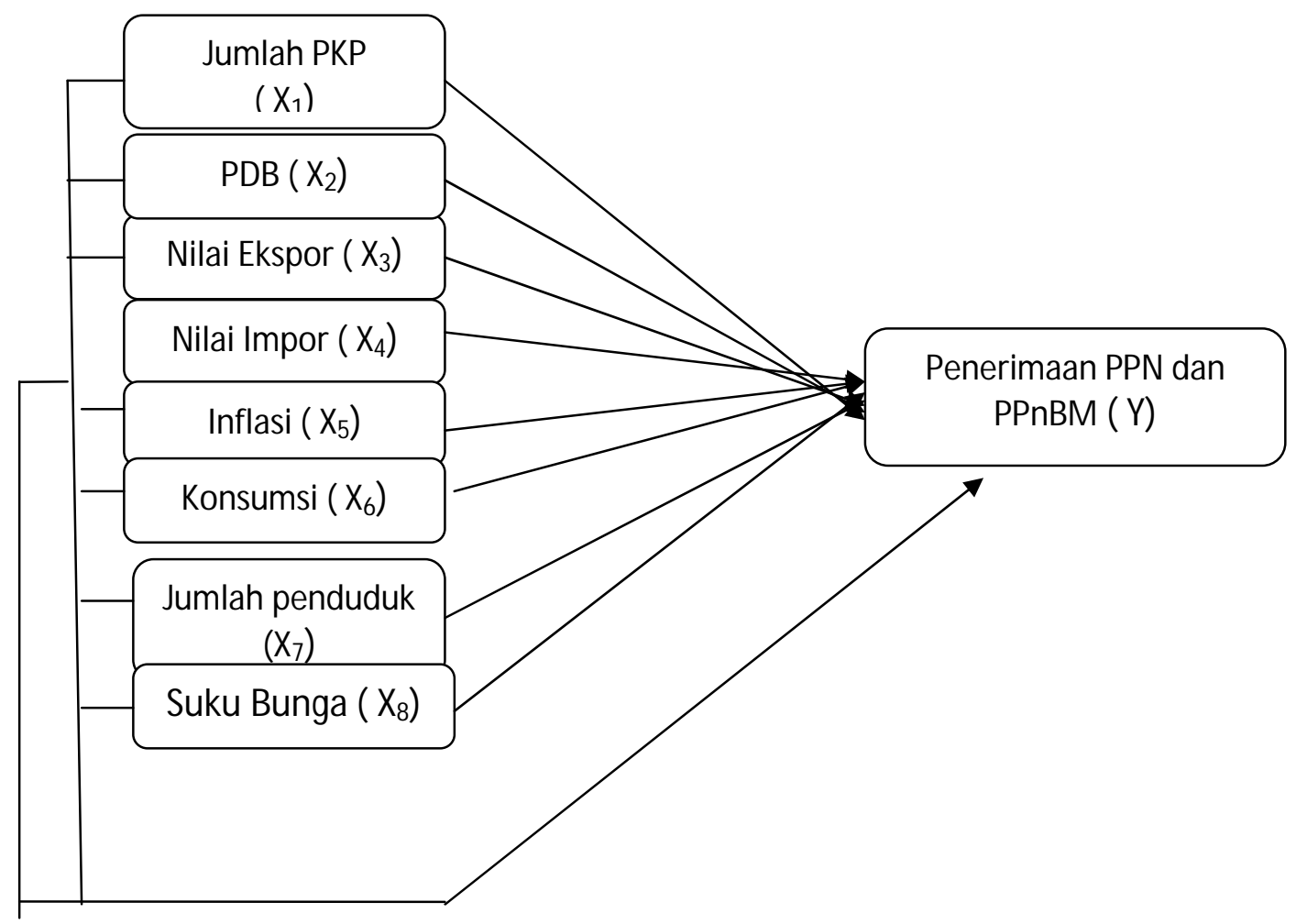

Gambar 2.1 Kerangka Konseptual

\section{METODE PENELITIAN}

Ruang lingkup penelitian ini adalah membahas perkembangan penerimaan PPN dan PPnBM serta faktor-faktor yang mempengaruhinya yaitu jumlah PKP, PDB, nilai ekspor, nilai impor, inflasi, pengeluaran konsumsi, jumlah penduduk dan suku bunga yang ada di Indonesia dalam kurun waktu tahun 1986 - 2015.

Jenis data dalam penelitian ini adalah data sekunder berupa data berkala (time series). Data yang digunakan adalah data tahunan dalam kurun waktu tahun 1986 - 2015 (30 tahun). Sumber data yang digunakan dalam penelitian ini berasal dari bahan-bahan bacaan yang berhubungan dengan penelitian, jurnal-jurnal, karya ilmiah, website yang memiliki kumpulan data yang dibutuhkan seperti website Badan Pusat Statistik, Direktorat Jenderal Pajak, Depertemen Keuangan dan Bank Indonesia serta penelitian-penelitian sebelumnya.

Variabel yang digunakan dalam penelitian ini adalah faktor-faktor yang mempengaruhi pajak pertambahan nilai dan pajak penjualan atas barang mewah (variabel dependen), dengan variabel independen sebagai 
indikator meliputi data $\operatorname{PKP}\left(X_{1}\right), \operatorname{PDB}\left(X_{2}\right)$, nilai ekspor $\left(X_{3}\right)$, nilai impor $\left(X_{4}\right)$, inflasi $\left(X_{5}\right)$, pengeluaran konsumsi $\left(X_{6}\right)$, jumlah penduduk $\left(X_{7}\right)$ dan Suku bunga $\left(\mathrm{X}_{8}\right)$.

Untuk mengetahui besarnya pengaruh dari suatu variabel bebas (independent variable) terhadap variabel terikat (dependent variable) maka penelitian ini menggunakan model regresi linear berganda (Multiple Linier Regression Methode) dengan metode kuadrat terkecil atau Ordinary Least Square (OLS) menggunakan bantuan software analisis data kuntitatif, Eviews 7. Metode ini diyakini mempunyai sifat-sifat yang ideal dan dapat diunggulkan, yaitu secara teknis sangat kuat, mudah dalam perhitungan dan penarikan interpretasinya (Gujarati, 2003).

Bentuk umum dari fungsi Penerimaan PPN dan PPnBM sebagai berikut, dengan Persamaan Regresi dinyatakan sebagai berikut:

$$
Y=\alpha+\beta_{1} X_{1}+\beta_{2} X_{2}+\beta_{3} X_{3}+\beta_{4} X_{4}+\beta_{5} X_{5}+\beta_{6} X_{6}+\beta_{7} X_{7}+\beta_{8} X_{8}+e
$$

Keterangan:

$\mathrm{Y}=$ Penerimaan PPN dan PPnBM (miliar rupiah)

$\mathrm{X}_{1}=$ Jumlah PKP (satuan/unit)

$\mathrm{X}_{2}=\mathrm{PDB}$ (miliar rupiah)

$\mathrm{X}_{3}=$ Nilai Ekspor (miliar rupiah)

$\mathrm{X}_{4}=$ Nilai Impor (miliar rupiah)

$\mathrm{X}_{5}=$ Inflasi (\%)

$\mathrm{X}_{6}=$ Konsumsi (miliar rupiah)

$\mathrm{X}_{7}=$ Jumlah penduduk (satuan/unit)

$\mathrm{X}_{8}=$ Suku bunga $(\%)$

$$
\alpha=\text { Konstanta }
$$

$\beta_{1} \beta_{2} \beta_{3} \beta_{4} \beta_{5} \beta_{6} \beta_{7} \beta_{8}=$ Koefisien regresi

$$
\mathrm{e}=\text { Kesalahan gangguan }
$$

atau dalam bentuk transformasi second difference:

$\mathrm{DY}=\mathrm{D} \alpha+\beta_{1} \mathrm{DX} \mathrm{X}_{1}+\beta_{2} \mathrm{DX}_{2}+\beta_{3} \mathrm{DX} \mathrm{X}_{3}+\beta_{4} \mathrm{DX} \mathrm{X}_{4}+\beta_{5} \mathrm{DX} \mathrm{X}_{5}+\beta_{6} \mathrm{DX} 6+\beta_{7} \mathrm{DX} 7+\beta_{8} \mathrm{X}_{8}+\mathrm{e} . .(2)$

Keterangan:

$\mathrm{Y}=$ Penerimaan PPN dan PPnBM (miliar rupiah)

$\mathrm{X}_{1}=$ Jumlah PKP (satuan/unit)

$\mathrm{X}_{2}=\mathrm{PDB}$ (miliar rupiah)

$\mathrm{X}_{3}=$ Nilai Ekspor (miliar rupiah) 


$$
\begin{aligned}
& \mathrm{X}_{4}=\text { Nilai Impor (miliar rupiah) } \\
& \mathrm{X}_{5}=\text { Inflasi (\%) } \\
& \mathrm{X}_{6}=\text { Konsumsi (miliar rupiah) } \\
& \mathrm{X}_{7}=\text { Jumlah penduduk (satuan/unit) } \\
& \mathrm{X}_{8}=\text { Suku bunga }(\%) \\
& \alpha=\text { Konstanta } \\
& \beta_{1} \beta_{2} \beta_{3} \beta_{4} \beta_{5} \beta_{6} \beta_{7} \beta_{8}=\text { Koefisien regresi } \\
& \mathrm{e}=\text { Kesalahan gangguan }
\end{aligned}
$$

Menurut Arief Daryanto dan Yundy Hafizrianda (2010:227) Adanya perbedaan dalam satuan dan besaran variabel bebas maka persamaan regresi dengan data yang tidak normal setelah di log, harus dibuat dengan model second difference.

\section{HASIL DAN PEMBAHASAN}

Model fungsi Penerimaan PPN dan PPnBM yang digunakan sebagai berikut:

$$
\mathrm{DY}=\mathrm{D} \alpha+\beta_{1} \mathrm{DX}_{1}+\beta_{2} \mathrm{DX} 2+\beta_{3} \mathrm{DX}+\beta_{4} \mathrm{DX} 4+\beta_{5} \mathrm{DX} 5+\beta_{6} \mathrm{DX}_{6}+\beta_{7} \mathrm{DX} 7+\beta_{8} \mathrm{DX}_{8+} \mathrm{e}
$$

Tabel 1.Jumlah PKP, PDB, Nilai Ekspor, Nilai Impor, Inflasi, Konsumsi, Jumlah .Penduduk, Suku Bunga terhadap Penerimaan PPN dan PPnBM

\begin{tabular}{ccccc}
\hline Variabel & Koefisien & $\begin{array}{c}\text { Invers.Second } \\
\text {.Difference }\end{array}$ & Prob. $\mathbf{~}$ & Keterangan \\
\hline Konstanta & 165914.6 & 4849,349 & 0,087 & Observasi (n) 30 \\
X1 & 0,002 & 0,0008 & 0,899 & \\
X2 & $-0,017$ & 36,563 & 0,887 & \\
X3 & $-0,007$ & 0,026 & 0,208 & \\
X4 & 0,733 & 0,528 & 0,022 & \\
X5 & $-136,841$ & $-0,067$ & 0,008 & \\
X6 & 0,082 & 0,042 & 0,179 & \\
X7 & $-0,001$ & 0,138 & 0,061 & \\
X8 & $-137,173$ & $-478,240$ & 0,034 & \\
$\mathbf{R}^{2}=0,686$ Prob. F $=0,001$ & & & \\
\hline
\end{tabular}

Sumber: data diolah

QE Journal |Vol.07 - N 0.01 M arch 2018 - 27 
Berdasarkan data sekunder diatas, untuk melihat pengaruh variabel Jumlah PKP, PDB, Nilai Ekspor, Nilai Impor, Inflasi, Konsumsi, Jumlah Penduduk, Suku Bunga terhadap Penerimaan PPN dan PPnBM dapat dianalisis koefisien statistik dari masing-masing variabel. Koefisien statistik dari masing-masing variabel independen dapat dihitung dengan bantuan komputer melalui program Eviews 7dengan hasil sebagai berikut diatas.

Berdasarkan hasil model estimasi fungsi Penerimaan PPN dan PPnBM yang disajikan pada tabel 1. diperoleh hasil persamaan sebagai berikut:

$\mathrm{Y}=4849,349+0,0008 \mathrm{X}_{1}+36,563 \mathrm{X}_{2}+0,026 \mathrm{X}_{3}+0,528 \mathrm{X}_{4}-0,067 \mathrm{X}_{5}+0,042 \mathrm{X}_{6}+$ $0,138 X_{7}-478,240 X_{8}$

Analisis hasil model estimasi tersebut dapat diinterpretasikan sebagai berikut:

\section{Pengaruh Variabel Secara Parsial}

Berdasarkan Tabel 1, dapat diketahui bahwa koefisien konstanta adalah 4849,349. Koefisien ini memberi makna bahwa dalam keadaan tetap atau tidak ada perubahan pada variabel Jumlah PKP $\left(\mathbf{X}_{\mathbf{1}}\right)$, PDB $\left(\mathbf{X}_{\mathbf{z}}\right)$, Nilai Ekspor $\left(\mathbf{X}_{\mathbf{3}}\right)$, Nilai Impor $(\mathbf{X}-\mathbf{4})$, Inflasi $(\mathbf{X}-5)$, Konsumsi $\left(\mathbf{X}_{6}\right)$, Jumlah Penduduk (X-7), Suku Bunga ( $\mathbf{X} \boldsymbol{- 8}$ ] maka nilai Penerimaan PPN dan PPnBM (Y) tetap sebesar 4849,349 miliar rupiah.

Berdasarkan Tabel 1. dapat diketahui bahwa koefisien Jumlah PKP hasil empiris sebesar 0,0008. Koefisien empiris variabel Jumlah PKP menunjukkan pengaruh yang positif yang memberi makna bahwa apabila Jumlah PKP bertambah sebesar satuan per tahun, maka akan menambah Penerimaan PPN dan PPnBM sebesar 0,0008 miliar rupiah. Berdasarkan Tabel 1. dapat diketahui bahwa koefisien PDB hasil empiris sebesar 36,563. Koefisien empiris variabel PDB menunjukkan pengaruh yang positif yang memberi makna bahwa apabila PDB bertambah sebesar satu miliar rupiah per tahun, maka akan menambah Penerimaan PPN dan PPnBM sebesar 36,563 miliar rupiah.

Berdasarkan Tabel 1. dapat diketahui bahwa koefisien Nilai Ekspor hasil empiris sebesar 0,026. Koefisien empiris variabel Nilai Ekspor menunjukkan pengaruh yang positif yang memberi makna bahwa apabila Nilai Ekspor bertambah sebesar satu miliar rupiah per tahun, 
maka akan menambah Penerimaan PPN dan PPnBM sebesar 0,026 miliar rupiah.

Berdasarkan Tabel 1. dapat diketahui bahwa koefisien hasil empiris sebesar 0,528. Koefisien empiris variabel Nilai Impor menunjukkan pengaruh yang positif yang memberi makna bahwa apabila Nilai Impor bertambah sebesar satu miliar rupiah per tahun, maka akan menambah Penerimaan PPN dan PPnBM sebesar 0,528 miliar rupiah.

Berdasarkan Tabel 1. dapat diketahui bahwa koefisien hasil empiris sebesar - 0,067. Koefisien empiris variabel Inflasi menunjukkan pengaruh yang negatif yang memberi makna bahwa apabila Inflasi bertambah sebesar satu persen per tahun, maka akan mengurangi Penerimaan PPN dan PPnBM sebesar 0,067 miliar rupiah. Berdasarkan Tabel 1. dapat diketahui bahwa koefisien hasil empiris sebesar 0,042. Koefisien empiris variabel Konsumsi menunjukkan pengaruh yang positif yang memberi makna bahwa apabila Konsumsi bertambah sebesar satu miliar per tahun, maka akan menambah Penerimaan PPN dan PPnBM sebesar 0,042 miliar rupiah.

Berdasarkan Tabel 1. dapat diketahui bahwa koefisien hasil empiris sebesar 0,138. Koefisien empiris variabel Jumlah Penduduk menunjukkan pengaruh yang positif yang memberi makna bahwa apabila Jumlah Penduduk bertambah sebesar satu jiwa per tahun, maka akan menambah Penerimaan PPN dan PPnBM sebesar 0,138 miliar rupiah. Berdasarkan Tabel 1. dapat diketahui bahwa koefisien hasil empiris sebesar - 478,240. Koefisien empiris variabel Suku Bunga menunjukkan pengaruh yang negatif yang memberi makna bahwa apabila Suku Bunga bertambah sebesar satu persen per tahun, maka akan mengurangi Penerimaan PPN dan PPnBM sebesar 478,240 miliar rupiah.

\section{Pengaruh Variabel Secara Serentak}

Berdasarkan hasil model estimasi pada Tabel 1. diketahui bahwa nilai prob. F $0,001<0,05$. Artinya semua variabel bebas, yaitu variabel Jumlah PKP $\left(\mathbf{X}_{\mathbf{1}}\right)$, PDB $\left(\mathbf{X}_{2}\right)$, Nilai Ekspor $\left(\mathbf{X}_{\mathbf{3}}\right)$, Nilai Impor $\left(\mathbf{X}^{\mathbf{4}} \mathbf{4} \mathbf{]}\right.$, Inflasi $\left(\mathbf{X}^{\mathbf{w 5}}\right)$, Konsumsi $\left(\mathbf{X}_{\mathbf{6}}\right)$, Jumlah Penduduk $(\mathbf{X} \mathbf{m})$, Suku Bunga $\left(\mathbf{X}^{\mathbf{w}} \mathbf{8}\right]$ secara bersama-sama berpengaruh secara signifikan terhadap Penerimaan PPN dan PPnBM pada tingkat kesalahan 5\%.

\section{Model Empiris}


Model statistik yang dibangun perlu diuji untuk mengukur seberapa jauh kemampuan model dalam menerangkan variasi variabel independen. Uji model estimasi dapat dilihat dari koefisien determinasi $\left(R^{2}\right)$ dengan keputusan:

- Bagus apabila $R^{2}>0,90$

- Kurang bagus apabila $50<R^{2}>0,90$

- Tidak bagus apabila $0<R^{2}<0,90$

Berdasarkan Tabel 1., hasil model empiris menunjukkan $\mathrm{R}^{2}$ sebesar 0,686 berada di antara $50<\mathrm{R}^{2}<0,90$. Hal ini memberikan makna bahwa model empiris yang dibangun tentang Penerimaan PPN dan PPnBM yang ditentukan oleh Jumlah PKP $\left(\mathbf{X}_{\mathbf{1}}\right)$, PDB $\left(\mathbf{X}_{2}\right)$, Nilai Ekspor $\left(\mathbf{X}_{3}\right)$, Nilai Impor (X-4], Inflasi (X-5), Konsumsi $\left(\mathbf{X}_{6}\right)$, Jumlah Penduduk $(\mathbf{X} \mathbf{\sim 7})$. Suku Bunga $(\mathbf{X} \mathbf{8}]$ adalah kurang bagus karena $R^{2}=0,686<0,90$.

Nilai koefisien determinasi (R Square) sebesar 0,686 memberi informasi bahwa secara bersama-sama variabel Jumlah PKP $\left(\mathbf{x}_{\mathbf{1}}\right)$, PDB $\left(\mathbf{X}_{2}\right)$, Nilai Ekspor $\left(\mathbf{X}_{3}\right)$, Nilai Impor $(\mathbf{X}-\mathbf{4}]$, Inflasi $(\mathbf{X}-5)$, Konsumsi $\left(\mathbf{X}_{\mathbf{6}}\right)$, Jumlah Penduduk (X-7), Suku Bunga $(\mathbf{X}-\mathbf{8})$ mampu memberikan variasi variabel Penerimaan PPN dan PPnBM sebesar 68,6 \%, sedangkan sisanya sebesar $31.4 \%$ dijelaskan oleh faktor lain yang tidak disertakan pada model estimasi yang dibangun.

\section{Uji Kesesuaian (Goodness Of Fit)}

Berdasarkan hasil estimasi diperoleh nilai koefisien determinasi $R^{2}(R$ Square) sebesar 0,686 atau 68,6\%. Hal ini menunjukkan bahwa persentase sumbangan pengaruh variabel independen Jumlah PKP $\left(\mathbf{x}_{\mathbf{1}}\right), \operatorname{PDB}\left(\mathbf{X}_{2}\right)$, Nilai Ekspor $\left(\mathbf{X}_{\mathbf{3}}\right)$, Nilai Impor $\left(\mathbf{X} \mathbf{- 4} \mathbf{]}\right.$, Inflasi (X-5), Konsumsi $\left(\mathbf{X}_{\mathbf{6}}\right)$, Jumlah Penduduk $(\mathbf{X}-\mathbf{7})$, Suku Bunga $(\mathbf{X}-\mathbf{8})$ mampu memberikan variasi variabel (Y) Penerimaan PPN dan PPnBM sebesar 68,6 \%,. Sedangkan sisanya sebesar 31,4\% dipengaruhi atau dijelaskan oleh variabel lain yang tidak dimasukkan dalam model penelitian ini.

Berdasarkan hasil perhitungan eviews 7 , Analisis regresi linier berganda adalah hubungan secara linier antara dua variabel atau lebih variabel independen dengan variabel dependen. Analisis ini untuk mengetahui arah hubungan antara variabel independen dengan variabel dependen apakah masing-masing variabel independen berhubungan positif atau QE Journal |Vol.07 - N o. 01 M arch 2018 - 30 
negatif dan untuk memprediksi nilai dari suatu variabel dependen apabila nilai variabel independen mengalami kenaikan atau penurunan.

Adanya perbedaan dalam satuan dan besaran variabel bebas maka persamaan regresi harus dibuat dengan model second difference. Untuk alasan pemilihan model logaritma natural adalah sebagai berikut :(a)Menghindari adanya heterokedatisitas; (b)Mengetahui koefisien yang menunjukkan elastisitas; (c)Mendekatkan skala data. Berdasarkan hasil model estimasi fungsi Penerimaan PPN dan PPnBM yang disajikan pada tabel 1. diperoleh hasil persamaan sebagai berikut:

$$
\begin{gathered}
Y=4849,349+0,0008 X_{1}+36,563 X_{2}+0,026 X_{3}+0,528 X_{4}-0,067 X_{5}+0,042 X_{6}+ \\
0,138 X_{7}-478,240 X_{8} \ldots \ldots . .(3)
\end{gathered}
$$

\begin{tabular}{|c|c|c|c|c|}
\hline $\begin{array}{r}\text { Dependen } \\
\text { Method: } \\
\text { Date: } 07 / 07 \\
\text { Sample (adj } \\
\text { Included obs }\end{array}$ & $\begin{array}{l}\text { Variable: D } \\
\text { east Squares } \\
17 \text { Time: } 15 \text { : } \\
\text { sted): } 19882 \\
\text { rrvations: } 28\end{array}$ & 22 & ents & \\
\hline Variable & Coefficient & Std. Error & $\mathrm{t}$-Statistic & Prob. \\
\hline $\mathrm{C}$ & 4849.349 & 2688.915 & 1.803460 & 0.0872 \\
\hline DX1 & 0.000819 & 0.006398 & 0.127991 & 0.8995 \\
\hline DX2 & 36.56341 & 255.0455 & 0.143360 & 0.8875 \\
\hline DX3 & 0.026635 & 0.020435 & 1.303391 & 0.2080 \\
\hline DX4 & 0.528341 & 0.211888 & 2.493489 & 0.0220 \\
\hline DX5 & -0.067040 & 0.022778 & -2.943200 & 0.0083 \\
\hline DX6 & 0.042712 & 0.030629 & 1.394490 & 0.1793 \\
\hline DX7 & 0.138541 & 0.069566 & 1.991524 & 0.0610 \\
\hline DX8 & -478.2404 & 210.0866 & -2.276397 & 0.0346 \\
\hline R-squared & 0.686334 & \multicolumn{2}{|c|}{ Mean dependent var } & 1778.818 \\
\hline Adjusted R-squared & 0.554264 & \multicolumn{2}{|c|}{ S.D. dependent var } & 18779.23 \\
\hline S.E. of regression & 12537.67 & \multicolumn{2}{|c|}{ Akaike info criterion } & 21.96595 \\
\hline Sum squared resid & $2.99 \mathrm{E}+09$ & \multicolumn{2}{|c|}{ Schwarz criterion } & 22.39416 \\
\hline Log likelihood & -298.5234 & \multirow{2}{*}{\multicolumn{2}{|c|}{$\begin{array}{l}\text { Hannan-Quinn criter. } \\
\text { Durbin-Watson stat }\end{array}$}} & 22.09686 \\
\hline F-statistic & 5.196743 & & & 2.012054 \\
\hline Prob(F-statistic) & 0.001528 & & \\
\hline
\end{tabular}

Tabel 2. Hasil Koefisien Regresi Linier Berganda

Sumber: Hasil Data Diolah

QE Journal |Vol.07 - No. 01 March 2018 - 31 
Berdasarkan hasil model estimasi fungsi Penerimaan PPN dan PPnBM yang disajikan pada tabel 2. diperoleh hasil persamaan sebagai berikut:

$$
\begin{gathered}
Y=4849,349+0,0008 X_{1}+36,563 X_{2}+0,026 X_{3}+0,528 X_{4}-0,067 X_{5}+0,042 X_{6}+ \\
0,138 X_{7}-478,240 X_{8} \ldots \ldots \ldots \ldots .(4)
\end{gathered}
$$

\section{SIMPULAN}

Berdasarkan hasil analisis data yang telah diuraikan pada bab sebelumnya, maka dapat diambil kesimpulan sebagai berikut:

1. Jumlah PKP $\left(X_{1}\right)$ memiliki pengaruh positif terhadap Penerimaan PPN dan PPnBM (Y) di Indonesia.

2. PDB $\left(\mathrm{X}_{2}\right)$ memiliki pengaruh positif terhadap Penerimaan PPN dan PPnBM (Y) di Indonesia.

3. Nilai Ekspor $\left(X_{3}\right)$ memiliki pengaruh positif terhadap Penerimaan PPN dan PPnBM (Y) di Indonesia.

4. Nilai Impor $\left(\mathrm{X}_{4}\right)$ memiliki pengaruh positif terhadap Penerimaan PPN dan PPnBM (Y) di Indonesia.

5. Inflasi memiliki pengaruh negatif terhadap Penerimaan PPN dan PPnBM (Y) di Indonesia.

6. Konsumsi $\left(\mathrm{X}_{6}\right)$ memiliki pengaruh positif terhadap Penerimaan PPN dan PPnBM (Y) di Indonesia.

7. Jumlah penduduk $\left(X_{7}\right)$ memiliki pengaruh positif terhadap Penerimaan PPN dan PPnBM (Y) di Indonesia.

8. Suku bunga $\left(\mathrm{X}_{8}\right)$ memiliki pengaruh negatif terhadap Penerimaan PPN dan PPnBM (Y) di Indonesia .

9. Jumlah PKP $\left(\mathbf{X}_{\mathbf{1}}\right)$, PDB $\left(\mathbf{X}_{2}\right)$, Nilai Ekspor $\left(\mathbf{X}_{3}\right)$, Nilai Impor $(\mathbf{X} \mathbf{4} \mathbf{4}]$, Inflasi ( $\mathbf{X}-\mathbf{5})$, Konsumsi $\left(\mathbf{X}_{\mathbf{6}}\right)$,Jumlah Penduduk ( $\left.\mathbf{X}-\mathbf{7}\right)$, dan Suku Bunga ( $\mathbf{X}-\mathbf{8})$ secara bersama-sama atau secara Simultan berpengaruh positif terhadap Penerimaan PPN dan PPnBM (Y) di Indonesia.

\section{DAFTAR PUSTAKA}

Gujarati, Damodar, (2003). Ekonomitrika Dasar, Terjemahan Sumarno Zain, Erlangga: Jakarta. 
Mardiasmo. 2006. Perpajakan: Edisi Revisi 2006. Yogyakarta: Andi

Republik Indonesia, Undang-Undang Nomor 42 Tahun 2009 tentang Perubahan Ketiga atas Undang-Undang Nomor 6 Tahun 1983 tentang Ketentuan Umum dan Tata Cara Perpajakan.

Waluyo.dan Ilyas 2000. Perpajakan Indonesia 1 \& 2. Edisi 6. Penerbit Salemba Empat. Jakarta.

Wibowo,Tri. 2000. Sampak Penerimaan Pajak Terhadap Pendapatan Nasional. Jurnal KIPAS. Vol. 2 (24), hal. 32-39. 